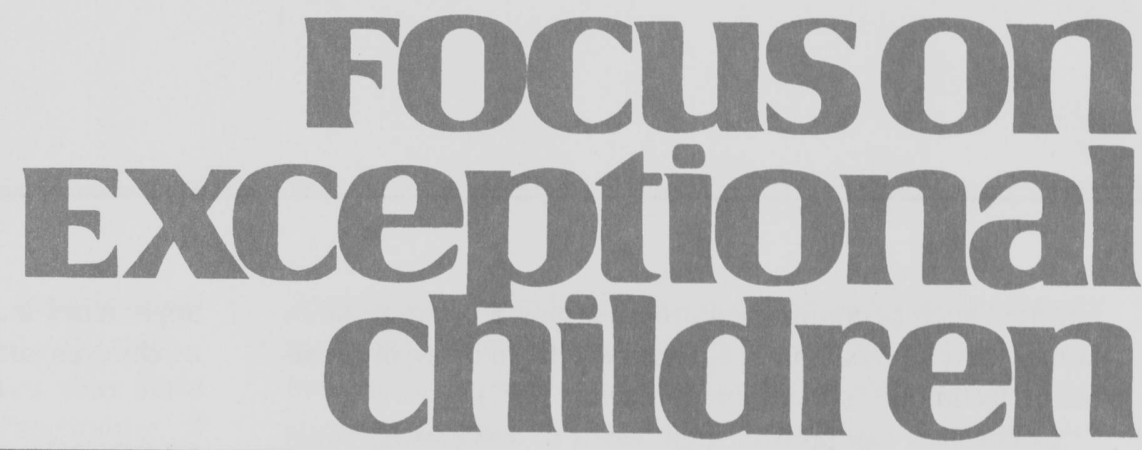

\title{
Counseling With Exceptional Children
}

\author{
Shari Tarver-Behring and Michael E. Spagna
}

Children and adolescents with disabilities are an extremely heterogeneous group of diverse learners, each with unique learning strengths and needs. Often misunderstood and frequently less served by the counseling profession, these children and adolescents need counseling services just as much as, if not more than, other children (McDowell, Coven, \& Eash, 1979). Federal legislation makes it imperative that all counselors who work with children and adolescents, even those not working within public school settings, be knowledgeable about the identification of and services for those with disabilities. In addition, all counselors have a professional and ethical responsibility to facilitate conditions that promote the full potential for all individuals, including exceptional groups (Baker, 1992; Holmgren, 1996; Maes, 1978; Seligman, 1985). As knowledge and experience are obtained for this population, counselors can serve children and their families more fully as intended by legal and professional guidelines.

Most counselors will encounter in their practice children and adolescents with disabilities. According to the U.S. Department of Education (2000), approximately 9\% of the school-age population is classified as having a federally recognized disability and, therefore, receiving special education and/or related services. This figure does not include gifted children, who also are significantly different from the norm and are in need of identification, curricular modifications, and counseling interventions (Silverman, 1993). Nor does it include students with disabilities who do not qualify for special education but may be eligible for other educational and counseling services.

Despite the number of children and adolescents with disabilities, counseling professionals historically have had limited contact with this population for a variety of reasons. Some counselors lack confidence and training to serve these groups. Some are uncomfortable around people with disabilities. Others have incorrect information about or prejudices toward those with exceptional needs (Tucker, Shepard, \& Hurst, 1986). In addition, because services to children and adolescents with disabilities are most often delivered by special education personnel within public schools, counselors may believe that their skills are not needed for these groups (Tarver Behring, Spagna, \& Sullivan, 1998). Most counselors, however, do have many of the skills needed to work with these children and their

Shari Tarver-Behring is a professor in the department of educational psychology and counseling at California State University at Northridge. Michael E. Spagna is a professor in the department of special education at California State University at Northridge. This article was adapted from Counseling Children and Adolescents published by Love Publishing Company. 
families, such as communication strategies, a background in human development, and experience with an array of therapeutic techniques (Cochrane \& Marini, 1977).

Counselors can prepare themselves to serve exceptional groups in several ways. As a first step, they must clarify their feelings and attitudes about working with children and adolescents who have disabilities. Pity, low expectations, repulsion to physical abnormalities, misinformation, and other biases can preclude effective counseling (Baker, 1992). Correct information and direct experience can facilitate accurate awareness and acceptance of these groups. In addition, counselors must obtain knowledge and training for working with specific groups with exceptional needs (Tarver Behring et al., 1998; Tucker et al., 1986). They can obtain this knowledge through training about federal and state guidelines, counseling workshops, consultation, supervision, current therapeutic literature, and community resources.

This article presents a discussion of identifying characteristics of children with developmental disabilities, physical and neurological disabilities, and attention deficit hyperactivity disorder, as well as a range of counseling

\section{Focuson
Exceptional children}

ISSN 0015-511X FOCUS ON EXCEPTIONAL CHILDREN (USPS 203-360) is published monthly except June, July, and August as a service to teachers, special educators, curriculum specialists, administrators, and those concerned with the special education of exceptional children. This publication is annotated and indexed by the ERIC Clearinghouse on Handicapped and Gifted Children for publication in the monthly Current Index to Journals in Education (CIJE) and the quarterly index, Exceptional Children Education Resources (ECER). The full text of Focus on Exceptional Children is also available in the electronic versions of the Education Index. It is also available in microfilm from Xerox University Microfilms, Ann Arbor, MI. Subscription rates: individual, \$36 per year; institutions, $\$ 48$ per year. Copyright (C) 2004, Love Publishing Company. All rights reserved. Reproduction in whole or part without written permission is prohibited. Printed in the United States of America. Periodical postage is paid at Denver, Colorado. POSTMASTER: Send address changes to:

Love Publishing Company

Executive and Editorial Office P.O. Box 22353

Denver, Colorado 80222

Telephone (303) 221-7333

\section{EDITORIAL BOARD}

Edwin Ellis

University of Alabama
Tim Lewis

University of Missouri

Chriss-Walther Thomas

University of Kansas

Susan T. Warhover Editor
Stanley F. Love Publisher approaches that have proven beneficial for specific groups of children and youth with disabilities.

\section{STUDENTS WITH DEVELOPMENTAL DISABILITIES}

Students with developmental disabilities, according to the Commission on Excellence in Special Education (U.S. Department of Education, 2002), include those having specific learning disabilities, speech and language impairments, emotional disturbance, mild mental retardation, and developmental delay. The categories of specific learning disabilities, emotional disturbance, and mild mental retardation are explored in more detail in the following discussion, which addresses the cognitive, academic, adaptive, social, perceptual-motor, and language functioning of students with these types of developmental disabilities.

\section{Categories of Students With Developmental Disabilities}

\section{Specific Learning Disabilities}

Children and adolescents who have been identified as having specific learning disabilities usually are eligible for special education and related services only if they exhibit average intellectual functioning. This eligibility criterion has created a great deal of controversy, as children and adolescents with above-average intellectual functioning also may benefit from services in certain areas. In direct comparison to students with mild mental retardation, who have global deficits in the areas of memory and attention, individuals with specific learning disabilities have difficulties in an encapsulated area or areas of cognitive functioning (e.g., phonemic awareness), which are referred to as psychological processing deficits. These deficits cause academic difficulties and result in achievement significantly below expectations given average intellectual capacity. The incidence of children and adolescents with specific learning disabilities has been reported at $4.5 \%$ for the 50 states and Washington, DC, for ages 6-21 during the 1999-2000 school year (U.S. Department of Education, 2001).

Adaptive functioning in students with specific learning disabilities, similar to cognitive ability, is relatively intact. Even though these children and adolescents might exhibit dependency on teachers and parents, they have learned in many instances how to compensate for the impact their disabilities have on life outside of school.

According to Henley, Ramsey, and Algozzine (1993), students with specific learning disabilities, similar to those with mild mental retardation, have low self-esteem and generally a poorly defined self-concept. Even more than individuals with mild mental retardation, these students want to be accepted by peers without disabilities, so much so that 
they place themselves particularly at risk for gang involvement, breaking the law, and substance abuse.

Students with specific learning disabilities may have absolutely no deficits in perceptual-motor functioning. If their specific learning disability does affect this area of functioning, however, as in individuals who have dysgraphia, their gross- and fine-motor skills may be so involved that even beginning handwriting skills might be affected.

In the area of language functioning, children and adolescents with specific learning disabilities may experience any of a multitude of difficulties in both receptive and expressive language. These deficits in language functioning might be evidenced by an inability to follow oral directions, to ask appropriate questions, to interact with peers socially, and so forth. Dysnomia, a type of specific learning disability that involves the inability to retrieve and express vocabulary, results in tip-of-the-tongue difficulties.

Cultural sensitivity should be considered in screening and referring students because a number of racial/ethnic subgroups have been misidentified for specific learning disabilities because of language differences, cultural mismatches in educational methodology, learning difficulties related to poverty, and teachers-versus-students cultural differences in behavioral expectations (American Youth Policy Forum and the Center on Educational Policy, 2002).

\section{Emotional Disturbance}

Cognitively, students with emotional disturbance usually are characterized as having at least low-average to average intellectual functioning and do not exhibit psychological processing deficits. According to the federal definition:

(i) The term [emotional disturbance] means a condition exhibiting one or more of the following characteristics over a long period of time and to a marked degree that adversely affects a child's educational performance:

(A) A.n inability to learn that cannot be explained by intellectual, sensory, or health factors.

(B) An inability to build or maintain satisfactory interpersonal relationships with peers and teachers.

(C) Inappropriate types of behavior or feelings under normal circumstances.

(D) A general pervasive mood of unhappiness or depression.

(E) A tendency to develop physical symptoms or fears associated with personal or school problems.

(ii) The term includes schizophrenia. The term does not apply to children who are socially maladjusted, unless it is determined that they have an emotional disturbance. (IDEA, 1997, sec. 300.7[4])

Students with emotional disturbance experience academic failure as a direct result of emotional problems or internalized and/or externalized behaviors that impact their performance. For example, students who have severe depression or suicidal ideation most certainly will encounter academic difficulties; pupils who are engaged in continuing behavioral outbursts (e.g., kicking other students) also will incur educational consequences - especially if they are suspended or expelled. Indeed, students with emotional disturbance often have discipline problems. The incidence of children and adolescents with emotional disturbance has been reported at $0.7 \%$ for the 50 states and Washington, DC, for ages 6-21 during the 1999-2000 school year (U.S. Department of Education, 2001)

As a result of their behavioral outbursts or generalized withdrawal, pupils with emotional disturbance tend to have poor relationships with their peers without disabilities. Like students with specific learning disabilities, they usually suffer from poor self-concept and low self-esteem. Often, their behaviors elicit negative reactions in peers, teachers, and parents that result in nonacceptance. As a result, these students are particularly susceptible to outside influences and are at risk for substance involvement, gang-related activity, and so forth.

Perceptual-motor skills and language functioning in this group are generally considered intact. But profane language and other behavioral outbursts resulting from emotional problems or socialized aggression can severely limit the interaction of these students with others.

As seen with the category of specific learning disabilities, African American students have been identified as having emotional difficulties at a higher rate than other cultural groups. Students from all cultural backgrounds must be understood and evaluated for emotional disorders in a culturally fair and appropriate manner (American Youth Policy Forum and the Center on Educational Policy, 2002).

\section{Mild Mental Retardation}

The incidence of mild mental retardation is approximately $1 \%$ in the 50 states and Washington, DC, for ages 6-21 during the 1999-2000 school year (U.S. Department of Education, 2001). Causes of mental retardation range from organic factors, such as Down syndrome, to environmental factors, such as fetal alcohol syndrome, malnutrition, and several known maternal infections (e.g., rubella).

Children and adolescents who have been identified as having mild mental retardation are determined eligible for special education and related services in accordance with federal law: "Mental retardation means significantly subaverage general intellectual functioning, existing concurrently with deficits in adaptive behavior and manifested during the developmental period, that adversely affects a child's educational performance" (IDEA, 1997, sec. 300.7[6]). As a direct result of their subaverage cognitive functioning, these children and adolescents generally learn at a slower pace than their peers without disabilities (Henley et al., 1993). They 
also avoid attempting new tasks and use inefficient learning strategies when faced with new tasks. In addition to having subaverage intellectual functioning, to be found eligible for special education and related services, these children and adolescents must be assessed as having below-average adaptive behaviors. Some poor adaptive behaviors found in students with mild mental retardation are poor self-help skills, low tolerance, low frustration and fatigue levels, and moral judgment commensurate with cognitive functioning.

Generally speaking, students with mild mental retardation are delayed in terms of social and emotional functioning. They usually exhibit lower levels of self-esteem and a more unfavorable self-concept than their peers without mental retardation. Because of their negative view of themselves, adolescents with mild mental retardation are overly susceptible to negative peer influences. Consequently, they might agree to experiment with foreign substances such as narcotics or to participate in gang-related activities in an attempt to gain peer acceptance (Polloway, Epstein, \& Cullinan, 1985).

Perceptual-motor and language functioning also are significantly delayed in children and adolescents with mild mental retardation. This below-average functioning particularly affects their ability to participate fully in physical education activities and negatively curtails their ability to communicate socially and interact with students without mild or moderate mental retardation.

African American students have been found to be identified in this category at a much higher rate than other racial/ethnic groups. All students should be screened, referred, and assessed for services with particular attention to approaching the needs of students in a culturally sensitive and fair manner (American Youth Policy Forum and the Center on Educational Policy, 2002).

\section{Counseling Students With Developmental Disabilities}

Several general guidelines are useful for counselors serving children and adolescents with developmental disabilities and their families. Of utmost importance, counselors must understand the characteristics and needs of these groups. Also crucial is familiarity with the criteria for qualifying for special educational categories and services, as outlined earlier, and familiarity with the rights of parents and children pertaining to these services. Counselors should advocate for culturally sensitive screening and consultation about alternative solutions in the general education classroom prior to referral and placement in special education (Tarver Behring \& Ingraham, 1998). Counselors also should support and participate directly in educational supports when academic difficulties are first evident (Echevarria, 2002). Counselors, too, must have general knowledge of the culturally fair methods and instruments for assessing children and youth in various categories.

Once an exceptional need has been identified, counselors may help by providing parents with referrals for various services, such as educational evaluations and services within the public school setting; health screenings; neurological evaluations; psychiatric assessments for medication; speech and language services, physical therapy, and career and vocational resources, both at school and in the community; specialized family counseling services; and support groups. Counselors then can consult with teachers, special educational personnel, parents, and community sources to plan educational and social interventions in a coordinated manner.

Planning should center on specific educational, behavioral, and emotional disabilities rather than abstract diagnostic categories (Westman, 1990). The student (especially if he or she is an adolescent) should be included in decision making about educational and therapeutic plans whenever possible. By including the child, he or she becomes educated about his or her strengths and weaknesses and feels mastery in helping to decide how to meet his or her special needs. Whenever possible, children and adolescents with mild and moderate disorders should be fully included in the general education classroom with appropriate modifications to allow for optimal educational and social opportunities.

Counselors also can help to promote social and emotional adjustment for children and adolescents with developmental disabilities (Tarver Behring et al., 1998). A number of sourcebooks are available offering intervention strategies, describing social skills programs, and listing therapeutic books for counselors to use with these children and adolescents as well as with their parents and teachers (Albrecht, 1995; Bloomquist, 1996; Pierangelo \& Jacoby, 1996; Rosenberg \& Edmond-Rosenberg, 1994; Sinason, 1997; S. L. Smith, 1991). In the school setting, counselors can assist the child or adolescent with developmental disabilities by consulting with teachers about social skills strategies and programs for the entire class. For example, through the guidance of counselors, teachers can act as role models by showing respect for all students and can help the class generate ground rules for classroom communication and give positive feedback to students without disabilities who are engaging in social interaction or academic activities with classmates with disabilities.

Both within and outside the school setting, counselors can work directly with children and adolescents with developmental disabilities through individual and group counseling on key social and emotional areas of difficulty, such as low self-esteem. Counselors can help these children and adolescents to build positive self-esteem by modeling appropriate ways to express feelings, teaching them how to think 
of alternative solutions to a problem, empowering these youngsters to be involved in decision making about themselves, creating opportunities for them to learn positive behavior through rewards and recurring successful experiences, providing them with accurate information about the disability, and identifying others with the disability who have succeeded (Pierangelo \& Jacoby, 1996).

Counselors also can work with the entire family on acceptance, goal setting, and rewards for success in the home to promote optimal conditions for these children and adolescents to reach their fullest potential. In addition, counselors can work with the family to facilitate the emotional adjustment of all family members by encouraging positive feelings for one another within the family, discussing how to balance attention for each child in the family, and specifying methods for support and stress reduction for the parents.

\section{Counseling Students With Specific Learning Disabilities}

Children and adolescents with specific learning disabilities need remedial services that target specific areas of functioning. Many of their other developmental areas are entirely normal and may even be areas of strength. These areas can be encouraged to promote overall adjustment in these individuals. Because most of the difficulties these children and adolescents experience are in academic areas, it is important to include teachers as team members when planning services for this group.

Federal law mandates inclusion in the general education classroom of children and adolescents with specific learning disabilities to the fullest extent possible. Therefore, counselors need to have contact with general education teachers and the resource specialists who provide specialized services to students with learning disabilities both inside and outside of the classroom (Tarver Behring \& Spagna, 1997; Tarver Behring et al., 1998). Counselors can consult with teachers about specific techniques (e.g., teaching the sequential-step approach to math problems, using repetition, teaching outlining techniques, and instructing students in the use of memory aids), classroom modifications (e.g., administering oral tests, using computers, audiotaping lectures, reducing assignments, and allowing extended time to complete work), and motivational approaches (e.g., employing internal and external reinforcers, token economies, and contracts for adolescents) that fit each student's special needs (Westman, 1990). Counselors who are less skilled in these interventions can team with the resource specialist to offer these services to the general education teacher. The partnership between special education and general education teachers is necessary for successful full inclusion, but it often does not happen without an advocate, because of time constraints, scheduling differences, and the differing roles of school personnel (Eichinger \& Woltman, 1993).

Social adjustment might be an additional area of need for students with specific learning disabilities, either because of weaknesses in social perception or of being viewed as different as a result of academic difficulties. Counselors can help teachers to be role models for the rest of the class in promoting social success for students with learning disabilities and can help them facilitate supportive peer activities such as peer pairing, cooperative work groups, and classroom social skills programs (Tarver Behring et al., 1998). When providing services to adolescents who are fully included in the general education classroom teachers should be discreet because of the importance of peer acceptance at this age.

Children and adolescents with specific learning disabilities also can benefit from having tutors outside of school to help with homework and test preparation. In addition, the tutors can help to reduce stress between the parents and child involving completion of academic activities and help the parents to further understand their child's or adolescent's educational needs (Westman, 1990).

If attention difficulties are present in combination with specific learning disabilities, counselors can recommend that parents consult with a psychiatrist about the possibility of prescribing stimulant medication for children who have not responded to other techniques (Barkley, 1995). Counselors, too, can work directly with children to help raise their low self-esteem and with adolescents about their identity issues and long-term career planning, in individual and group counseling settings. Finally, counselors can offer support to parents in relation to specific difficulties and demands in the home: tutorial services to reduce parents' stress surrounding schoolwork demands; assistance in developing schedules to help parents who are frustrated because of their children's lack of organization; and referral of children to social organizations to address parents' concerns about their children's low self-esteem, social status, and long-term educational and career adjustment (Westman, 1990).

\section{Counseling Students With Emotional Disturbance}

Children and adolescents with emotional disturbance are most in need of stable, supportive environments that offer emotional nurturance, clear behavioral rules, and limits (Thompson \& Rudolph, 1988). To maximize the effectiveness of treatment, counselors should be familiar with the various emotional and behavioral disorders of childhood and adolescence from both an educational and a psychological perspective (American Psychological Association, 1994; Individuals with Disabilities Education Act, 1997). 
At school, students with emotional disturbance can benefit greatly in educational and emotional/social areas alike from inclusion in general education programs and activities when their inclusion is planned properly (Colvin, Karmeenui, \& Sugai, 1994; Keenen, 1993). Counselors can help parents advocate that educational strategies and behavioral plans for their child are developed and fully implemented in the general education classroom setting. Because counselors have expertise in assisting with social and behavioral adjustment, they can consult with teachers about how to be appropriate role models, how to pair children with peer mentors in classroom activities, and how to identify ground rules for communication and behavior for the whole class (Kramer \& Wright, 1994).

Counselors can provide teachers with social skills strategies and programs for the classroom that focus on problem solving, conflict resolution, anger management, and friendship making (Tarver Behring et al., 1998). For example, an elementary-age child with emotional disturbance can benefit from clear classroom rules, rewards, and consistent consequences; journaling about feelings; bibliotherapy; discreet prompts from the teacher, such as a gentle touch, to help the child be aware of inappropriate behavior before it escalates; brainstorming various solutions and consequences about friendship problems; being paired with a high social-status peer mentor in school activities; working on goal-oriented projects; and participating in activities with other children in areas in which he or she can be successful. Counselors can provide guidance in all of these areas.

Counselors also may be called upon to provide any of a number of counseling services that are critical for the adjustment of children and adolescents with emotional disturbance. Counselors working with these children and their families should have training in crisis counseling, the mandated reporting laws for child abuse, suicidal behavior, and intent to harm others, to name just a few essential areas, so they can be of assistance to students, parents, and teachers in these areas if needed. Counselors also can offer behavioral strategies and parent training to parents. Especially helpful for parents of adolescents with emotional disturbance is training in creating and using contracts that clearly specify limits, rules, expected behaviors, privileges, and consequences for inappropriate behaviors.

Even though families may contribute to the behavioral and emotional disorders of children and adolescents when discipline is harsh or inconsistent, a child's difficulties often are caused less directly by the parenting style alone than by a negative cycle in which the parents lack coping skills and strategies to deal with the youngster's difficult temperament (Patterson, 1986). Therefore, family therapy is strongly recommended to resolve anger and negative interaction patterns in the family. Individual and group counseling can be beneficial with children and adolescents who have mild and moderate emotional problems. Through individual counseling, the counselor can build a therapeutic, supportive relationship and work to change the child's or adolescent's negative self-image, depressed or anxious feelings, or relationship difficulties with peers. Group counseling can help the child or adolescent learn to express feelings more appropriately and can help the child or adolescent develop a positive self-concept, improve social skills and academic performance, and increase motivation. Planning educational and career goals with adolescents, parents, and teachers can provide positive alternatives to help the adolescent with a mild or moderate emotional or behavioral disorder toward long-term adjustment (Kauffman, 1997).

\section{Counseling Students With Mild Mental Retardation}

Students with mild mental retardation must meet criteria generally aligned with the widely accepted definition of mental retardation proposed by the American Association on Mental Retardation (AAMR, 1992), which states:

\begin{abstract}
Mental retardation refers to substantial limitations in present functioning. It is characterized by significantly subaverage intellectual functioning, existing concurrently with related limitations in two or more of the following applicable adaptive skill areas: communication, self-care, home living, social skills, community use, self-direction, health and safety, functional academics, leisure and work. Mental retardation manifests before age 18 . (p. 1)
\end{abstract}

Because they experience developmental delays in most areas of functioning, children and adolescents with mild mental retardation require multiple services. Counselors can help to coordinate school, home, and community services for all areas of need. In the school setting, children and adolescents with mild and moderate mental retardation will benefit in educational and social areas alike by being fully included in the general educational program (Stevens \& Slavin, 1991). Counselors, therefore, often work with parents, special educators, and teachers to advocate for appropriate educational modifications and resources in the general education classroom. They can help teachers to promote social adjustment for these students by providing guidance in incorporating peer modeling, self-reliance, age-appropriate social behavior, and friendship-making skills into classroom activities (Tarver Behring et al., 1998). They can promote tolerance of differences in peers without disabilities through social skills programs, integrated counseling groups, and classroom modeling and discussion (Frith, Clark, \& Miller, 1983; Gottlieb, 1980; Salend, 1983). Further, they can teach behavioral modification, token economy, and contingency contracting strategies to teachers and parents to assist them in helping the students develop appropriate 
academic, social, and self-help behaviors (Cochrane \& Marini, 1977).

Although the value of counseling with this group is controversial because of the students' cognitive limitations, it seems reasonable that counselors can offer individual and group counseling focusing on self-esteem, self-expression, and behavioral rehearsal, which are all typical areas of need (Thompson \& Rudolph, 1988). Counselors can help parents understand and encourage their child's or adolescent's abilities and help the parents cope with the stresses of parenting a disabled child. For adolescents, special attention should be given to their developing independent living skills and to educational and vocational planning.

\section{STUDENTS WITH PHYSICAL AND NEUROLOGICAL DISABILITIES}

According to the Commission on Excellence in Special Education (U.S. Department of Education, 2002), students with physical and neurological disabilities include students having orthopedic impairments, other health impairments, traumatic brain injury, multiple disabilities, and autism. The categories of orthopedic impairments and multiple disabilities are described in more detail next, addressing the cognitive, academic, adaptive, social, perceptual-motor, and language functioning of students who have these forms of physical and neurological disabilities.

\section{Categories of Physical and Neurological Disabilities}

\section{Students With Orthopedic Impairments}

The incidence of orthopedic impairments is approximately $0.1 \%$ in the 50 states and Washington, DC, for ages 6-21 during the 1999-2000 school year (U.S. Department of Education, 2001). Federal law describes children and adolescents with orthopedic impairments in the following manner:

\footnotetext{
Orthopedic impairment means a severe orthopedic impairment that adversely affects a child's educational performance. The term includes impairments caused by congenital anomaly (e.g., clubfoot, absence of some member, etc.), impairments caused by disease (e.g., poliomyelitis, bone tuberculosis, etc.), and impairments from other causes (e.g., cerebral palsy, amputations, and fractures or burns that cause contractures). (IDEA, 1997, sec. 300.7[8])
}

Musculoskeletal impairments usually result in severe restriction of movement, typically affecting both gross- and fine-motor movements, as a result of stiffening of joints, inflammation of bones, degeneration of muscle fiber and bone structure, and muscle atrophy resulting from lack of use. In addition to influencing range of motion, severe musculoskeletal impairments can cause children and adolescents to become extremely embarrassed and frustrated because they are so dependent on others for assistance. These impairments include arthrogryposis multiplex congenita (also known as Pinocchio syndrome due to the wooded appearance of the individuals affected), osteogenesis imperfecta (also known as brittle bone disease), juvenile rheumatoid arthritis, and muscular dystrophy.

Spinal cord impairments, as the name implies, involve a disabling condition whereby the spinal cord is severed or injured resulting in anything from incoordination to partial to full paralysis below the point of nerve damage. Children and adolescents with severe spinal cord injuries may also suffer from a variety of skin, urinary, and respiratory infections, insensitivity to heat and cold, and inability to control bowel and bladder functions. Severe spinal cord impairments include spina bifida and spinal muscular dystrophy.

Cerebral palsy and several seizure disorders are considered orthopedic impairments that can result in severe physical difficulties. As opposed to spinal cord impairments, cerebral palsy involves dysfunction of the brain and nervous system (not including the spinal cord) that results in difficulty with gross- and fine-motor skills, attention, eye-hand coordination, and so forth.

\section{Students With Multiple Disabilities}

According to the U.S. Department of Education (2001), $0.2 \%$ of the school-age population in the United States is considered to have multiple disabilities and, therefore, receives special education and related services. Although it is easy to think of multiple disabilities as an accumulation of several of the categories covered so far, in fact, students who have multiple disabilities experience difficulties that are magnified beyond a simple analysis of the sum of the parts. The combinations of disabilities are endless. Mild mental retardation, for example, can co-occur with cerebral palsy, with a variety of orthopedic impairments such as those already presented, or with a range of severe behavior disorders, as well as with visual and/or hearing impairments. Emotional disturbance can also coexist with a full range of physical, visual, and/or hearing impairments.

\section{Counseling Students With Physical and Neurological Disabilities}

The best approach for counselors involved with children and adolescents who have physical and neurological disabilities is to work closely with the multidisciplinary team of the school's special educational personnel, physicians, community specialists, and personnel from governmental services (such as vocational counselors), who provide the primary services to these students. These experts can determine the student's strengths and needs and how best to offer support. 
Counselors can consult with these personnel and assist parents in understanding, accessing, and advocating for programs that will help their child or adolescent to reach his or her fullest potential.

Counselors also can offer parents individual, group, or family counseling involving issues of grief surrounding their child's disability, issues of guilt, and issues of hopelessness in viewing their child's future (Thompson \& Rudolph, 1988). By the time the child with physical and neurological disabilities reaches age 16, a transition plan should be in place as a part of the child's individualized education program, offering support in work, home, recreation, and community activities and promoting optimal long-term adjustment (Downing, 1996).

\section{Counseling Students With Orthopedic Impairments}

In counseling with children and adolescents who have orthopedic impairments, the client's strengths as well as disabilities must be recognized. Frequently, individuals who associate with these children and adolescents overlook their strengths by assuming deficits in all domains based upon the child's physical appearance. Often, the low self-esteem of these children and adolescents derives as much from having unrecognized strengths as from self-consciousness resulting from a physical disorder. In addition to supporting the child's strengths and helping the child to work with his or her disability, the counselor can assist parents in advocating for appropriate assessment and services at school and through community resources.

These children and adolescents should be included to the maximum extent possible to allow for optimal educational, self-care, vocational, and social opportunities (Downing, 1996). Counselors can coordinate services with other specialists to help parents and teachers reorganize physical environments, remove barriers, and obtain special equipment to facilitate inclusion in all areas of life. Counselors also can help parents and teachers avoid overprotectiveness and assist these children and adolescents in reaching their full potential (Thompson \& Rudolph, 1988).

\section{Counseling Students With Multiple Disabilities}

To coordinate services for children or adolescents with multiple disabilities, the counselor must understand disabilities in multiple areas and has to work with all involved parties. Most of the previous suggestions apply to counseling members of this group and their families, depending on which combinations of disabilities are present. Counselors can assist parents by advocating for school and community services, requesting appropriate modifications and aids, and offering supportive counseling. They also can help the students directly in the areas of self-esteem, self-help, and social skills if they have a high enough level of communication and cognitive functioning. Finally, counselors should help develop, with the parents and IEP team, a plan to promote the long-term adjustment of these children and adolescents in multiple areas.

\section{STUDENTS WITH ATTENTION DEFICIT HYPERACTIVITY DISORDER}

Attention deficit hyperactivity disorder (ADHD) is a high-incidence disorder of children in the United States and a common reason for referral for special services. It is believed to occur in 10\%-20\% of children and adolescents and appears more frequently in males than females (Barkley, 1990; Rief, 1993; Silver, 1992). The Diagnostic and Statistical Manual of Mental Disorders (DSM-IV) defines the disorder as the presence of developmentally inappropriate hyperactivity, inattention, and impulsivity that is evident in the child by age 7 and leads to clinically significant impairment in social, academic, or occupational functioning across two or more settings, such as home and school (American Psychological Association, 1994). Inattention includes behaviors such as difficulty in sustaining task-related attention, listening, following instructions, and organization; distractibility; and forgetfulness. Hyperactivity/impulsivity includes fidgeting, out-of-seat behavior, restlessness, overactivity, excessive talking, interrupting others, difficulty awaiting one's turn, and responding impulsively to questions.

\section{Categories of Students With ADHD}

Three subtypes of ADHD are now recognized in the DSM-IV:

1. ADHD, Predominately Inattentive Type: Six or more inattentive symptoms but fewer than six hyperactive-impulsive symptoms are present.

2. ADHD, Predominately Hyperactive-Impulsive Type: Six or more hyperactive-impulsive symptoms but fewer than six inattentive symptoms are present.

3. ADHD, Combined Type: Six or more inattentive symptoms and six or more hyperactive-impulsive symptoms are present.

Without treatment, ADHD symptoms often persist throughout adolescence and adulthood; with treatment, the symptoms often decrease (Barkley, 1990). According to a theory developed by Barkley (1995), a delay in the development of behavioral inhibition could be the primary cause underlying all of the symptoms of ADHD.

The cause of ADHD is unclear. A variety of factors are associated with ADHD. Neurological variables and hereditary influences are the most likely factors. Diet and environmental 
toxins do not seem to significantly contribute to the presence of ADHD (Barkley, 1990).

Children and adolescents with ADHD may or may not qualify for educational services. Although these children and adolescents frequently have some form of academic difficulty, such as attentional or organizational problems, their achievement problems aren't always severe enough to fall into a special education category. Children and adolescents with ADHD qualify for special education services when the ADHD occurs in combination with another disability, such as a specific learning disability, or when the ADHD symptoms are so severe that achievement is delayed to the extent that the child or adolescent qualifies for the special education category entitled other health impairment.

Frequently, children and adolescents with ADHD qualify under Section 504 guidelines for educational modifications; that is, they exhibit symptoms that affect learning to the extent that reasonable educational modifications are required, such as implementation of a behavioral management program; placement in a small, highly structured classroom; counseling; and the administration of medication (Zirkel \& Gluckman, 1997). Classroom modifications and interventions for the child or adolescent with ADHD usually are necessary regardless of whether the child qualifies for specific educational services.

Children who have ADHD often are first identified at school, where their behavioral problems stand out in contrast to other children. To accurately assess for ADHD, DuPaul and Stoner (1994) recommended that the initial screening be followed by multiple assessment techniques such as rating scales, behavioral observations, and evaluation of academic and organizational skills in both home and school settings.

\section{Counseling Children and Adolescents With ADHD}

Multiple interventions are recommended for effectively treating the child or adolescent with ADHD (DuPaul \& Stoner, 1994). Barkley (1995) recommended that naturalistic interventions such as behavioral modification, cognitive strategies, teacher consultation, and social skills training be implemented at home and at school before considering the use of stimulant medication, which sometimes results in side effects. Stimulant medication has been found to be especially beneficial with more severe cases of ADHD (Barkley, 1990).

\section{Behavioral Modification}

One of the most effective treatments that counselors can use to change behavior in children with ADHD is behavioral modification (Barkley, 1990). With this approach, counselors can teach parents positive reinforcement strategies that can increase the child's task-related attention and activity and decrease his or her disruptive behavior in the home. Ideally, preferred activities rather than concrete rewards should be used as reinforcement; frequent and specific behavioral feedback should be given; and redirection and/or mild consequences should be used following inappropriate behavior (DuPaul \& Stoner, 1994).

\section{Cognitive Behavioral Training}

The cognitive behavioral training approach focuses on teaching self-control through strategies such as self-monitoring, self-instruction, and self-reinforcement. With the self-monitoring strategy, the child or adolescent with ADHD uses self-reminder statements to increase awareness and control of his or her behavior when direct feedback is not available (Taylor, 1994). With the self-instruction strategy, the child learns to follow a set of self-directed instructions for completing class work. Self-reinforcement operates on a principle similar to self-monitoring-teaching the child ways to praise himself or herself or to give himself or herself a reward, such as a check mark on a behavioral chart following positive behavior when external reinforcers are unavailable. Research indicates that these approaches typically are effective only for the specific situation in which they were taught and do not continue without the ongoing monitoring and encouragement of a counselor, parent, or teacher; therefore, cognitive behavioral training should be used in combination with other interventions and not as the only treatment strategy (Barkley, 1995).

\section{Teacher Consultation}

Counselors can consult with teachers to set up schoolbased interventions for children and adolescents with ADHD. These include the use of behavioral techniques, such as modeling, token economies, and home-school reward systems. Other classroom strategies include adapting instruction to highlight the main idea, giving the students prompts to respond, teaching the students to use organizers, working with them in small groups, using visual aids, and teaching problem-solving strategies (Kling, 1997). Teachers also should offer structure, supervision, and support in classroom activities (Taylor, 1994).

\section{Social Skills Training}

Programs that promote social adjustment can be beneficial for helping children and adolescents with ADHD. Social skills interventions for this population, however, should always be planned for specific settings, as social skills training does not automatically generalize to new social situations for the child or adolescent with ADHD (Barkley, 1990). Among the social problems that children and adolescents with ADHD exhibit are aggression, impulsive or intrusive 
conversational style, poor social problem solving, excessive talking, limited self-awareness, emotional overreactivity, and bossiness when initiating interactions (Guevremont, 1992). These social problems may lead to peer rejection and lower self-esteem, further complicating social adjustment.

Several general social skills instructional programs are available for counselors to use with children or adolescents with ADHD individually, in groups, or in classroom settings (Bender, 1997). One effective social skills program specifically designed for adolescents with ADHD targets methods for joining social exchanges, conversational skills, conflict resolution, and anger control (Guevremont, 1990). This program also involves peer models, strategies for maintaining social success, and cognitive strategies.

\section{Stimulant Medication}

Counselors can recommend screening for medication for the child or adolescent with ADHD. Two medications that have been found to improve behavioral, academic, and social functioning on a short-term basis are Ritalin and Cylert (DuPaul \& Barkley, 1990). Initial research indicated that $70 \%-80 \%$ of hyperkinetic children responded positively to initial doses of stimulant medication, with the most notable improvement seen in the area of attention span (Barkley, 1977). But not all children and adolescents with ADHD respond to this medication, and some may experience side effects. For these reasons, careful screening for the severity of ADHD must be done to determine if drug administration is warranted. If medication is prescribed, it must be accompanied by ongoing drug monitoring by qualified physicians and child psychiatrists.

Although early research failed to show that stimulant medications improved academic performance in hyperkinetic children as measured by standardized tests (Barkley \& Cunningham, 1978), more recent studies have indicated improvements in assignments and test scores in adolescents with ADHD taking stimulant medication (Pelham, VoddeHamilton, Murphy, Greenstein, \& Vallano, 1991). Most interventions for ADHD, including cognitive interventions (Barkley, 1989), behavioral therapy (Gomez \& Cole, 1991), and parent training (Horn, 1991), seem to be more effective for improving behavior in children and adolescents with ADHD, especially when ADHD is severe, when these interventions are used in combination with stimulant medication.

\section{Family Counseling}

Families with a child or an adolescent with ADHD can benefit from counseling for difficulties linked to having a family member with this disorder. For example, the parents and ADHD child may develop codependency as the parents try to establish normalcy through solving problems, organizing work, directing impulse control, completing tasks, and guiding social situations for the child who has difficulty in these areas. In addition, the family might experience stress directly related to the child's difficulties. For instance, the child's impulsivity and overactivity may keep the family in a constant state of arousal, and the child's inattention may require the parents' hypervigilance and repeated reminders (Bender, 1997). Adolescents with ADHD may lie, steal, skip school, and exhibit similar antisocial behaviors (Barkley, 1990).

A number of family interventions are available for helping a family with a child or adolescent with ADHD (Barkley, 1995; Bender, 1997). Through family counseling, the counselor can help all family members to acquire knowledge, understanding, and strategies for coping with the child or adolescent with ADHD without neglecting the needs of other family members. For example, parents can learn to channel their child's energies into productive activities that allow the child to attain success. Further, the counselor can help the family envision a positive future for the child by informing the parents and child of college academic and vocational options and services available for adolescents with ADHD.

\section{Support Groups}

Parents of children and adolescents with ADHD can benefit from support groups that target stress, guilt, and codependency issues. Parents find comfort when they realize that they are not alone in their feelings. The support group meetings can include lectures, demonstrations, question-and-answer sessions, or informal discussions. Counselors can help parents locate a recognized support group, such as CHADD (Children and Adolescents with Attention Deficit Disorder) or ADDA (Attention Deficit Disorder Association).

Counselors also can facilitate their own local ADHD parent support groups. These groups often are organized around specific topics. A session on prescribed medications, for example, could feature discussion by a qualified speaker or a group of experts having different points of view. Other topics might focus on how parents can help their children with ADHD in specific problem areas, such as anger control. A session on anger control might involve teaching parents to role-model appropriate anger for their child, to encourage their child to self-monitor anger, and to administer rewards to the child for the appropriate expression of anger (Taylor, 1994).

\section{Parenting Programs}

Parent education programs are available for counselors to use with parents of children with ADHD. These include the Barkley Parent Training Program (Barkley, 1990), the Patterson Parent Training Program (Newby, Fischer, \& Roman, 
1991), and Forehand and McMahon's Parent Training Program (Forehand \& McMahon, 1981). All of these programs cover ADHD behaviors and related parenting skills; methods for consistent, positive consequences for positive behaviors; and punishment through time-out for negative behaviors.

Parents can learn to use behavioral charts with younger children. The charts list three or four target behaviors in the home, and the children earn reinforcers each time the child performs a positive behavior. With adolescents, behavior can be managed through behavioral contracts negotiated with the teenager that specify ways to earn social activities and age-appropriate rewards (such as use of the family car).

\section{Direct Counseling}

Individual and group counseling can be offered to children and adolescents with ADHD to help them with issues of self-esteem and self-control. These individuals often feel low self-worth as a result of repeated negative feedback about their behavior. Among the therapeutic books available for use in counseling children with ADHD are I Would If I Could (Gordon, 1992) and Putting on the Brakes (Quinn, 1992). And games and other activities targeting ADHD behaviors are available for the counseling setting (Taylor, 1994). Group counseling can help these children and youth feel less different and more supported. Adolescent groups can promote the identification of positive role models and can help members set long-range goals as a tool for seeing themselves as having the potential for success. To help children and adolescents with ADHD maintain attention and behavior during direct counseling, structured, time-limited sessions and more directive approaches are recommended.

\section{SUMMARY}

Exceptional children and adolescents comprise a diverse and complex group requiring a wide range of services according to their individual needs. Counseling with children and adolescents with exceptional needs must be coordinated with educational services, medical and remedial specialists, family members, and the students themselves. Exceptional children and adolescents receive maximal benefits when comprehensive counseling services are offered in combination with a variety of other support services in the most normalized environment possible.

\section{REFERENCES}

Albrecht, D. G. (1995). Raising a child who has a physical disability. New York: Wiley.

American Association on Mental Retardation. (1992). Mental retardation: Definition, classification, and systems of supports (9th ed.). Washington, DC: Author.
American Psychological Association. (1994). Diagnostic and statistic manual of mental disorders (4th ed.). Washington, DC: Author.

American Youth Policy Forum and Center on Educational Policy. (2002). Twenty-five years of educating children with disabilities: The good news and the work ahead. Washington, DC: Author.

Baker, S. B. (1992). School counseling in the twenty-first century. New York: Merrill.

Barkley, R. A. (1977). The effects of methylphenidate on various measures of activity level and attention in hyperkinetic children. Journal of Abnormal Child Psychology, 5, 351-369.

Barkley, R. A. (1989). Attention-deficit hyperactivity disorder. In E. J. Mash \& R. A. Barkley (Eds.), Treatment of childhood disorders (pp. 39-72). New York: Guilford.

Barkley, R. A. (1990). Attention-deficit hyperactivity disorder: A handbook for diagnosis and treatment. New York: Guilford

Barkley, R. A. (1995). Taking charge of ADHD. New York: Guilford.

Barkley, R. A., \& Cunningham, C. E. (1978). Do stimulant drugs improve academic performance of hyperkinetic children? A review of outcome research. Journal of Clinical Pediatrics, 17, 85-92.

Bender, W. N. (1997). Understanding ADHD: A practical guide for teachers and parents. Englewood Cliffs, NJ: Prentice-Hall.

Bloomquist, M. L. (1996). Skills training for children with behavioral disorders: A parent and therapist guidebook. New York: Guilford.

Cochrane, P. V., \& Marini, B. (1977). Mainstreaming exceptional children: The counselor's role. School Counselor, 25, 17-21.

Colvin, G., Karmeenui, E. J., \& Sugai, G. (1994). Reconceptualizing behavior management and school-wide discipline in general education. Education and Treatment of Children, 16, 361-381.

Downing, J. E. (1996). Including students with severe and multiple disabilities in typical classrooms. Baltimore: Paul H. Brookes.

DuPaul, G. J., \& Barkley, R. A. (1990). Medication therapy. In R. A. Barkley (Ed.), Attention-deficit hyperactivity disorder: A handbook for diagnosis and treatment (pp. 573-612). New York: Guilford.

DuPaul, G. J., \& Stoner, G. (1994). ADHD in the schools: Assessment and intervention strategies. New York: Guilford.

Echevarria, J. (2002, March 15). The disproportionate representation of minority students in special education: Where do we go from here? Paper presented at Oxford Round Table on Education and Human Rights at Oxford University, Oxford, England.

Eichinger, J., \& Woltman, S. (1993). Integration strategies for learners with severe multiple disorders. Teaching Exceptional Children, 26, 18.

Forehand, R. L., \& McMahon, R. J. (1981). Helping the noncompliant child: A clinician guide to parent training. New York: Guilford.

Frith, G. H., Clark, R. M., \& Miller, S. H. (1983). Integrated counseling services for exceptional children: A functional, noncategorical model. School Counselor, 30, 387-391.

Galvin, M. (1988). Otto learns about his medicine. New York: Magination.

Gomez, K., \& Cole, C. (1991). Attention deficit hyperactivity disorder: A review of treatment alternatives. Elementary School Guidance and Counseling, 26, 106-114.

Gordon, M. (1992). I Would If I Could. DeWitt, NY: GCL.

Gottlieb, J. (1980). Improving attitudes toward retarded children by using group discussion. Exceptional Children, 47, 106-111.

Guevremont, D. (1990). Social skills and peer relationship training. In R. A. Barkley (Ed.), Attention-deficit hyperactivity disorder: A handbook for diagnosis and treatment (pp. 540-572). New York: Guilford.

Guevremont, D. (1992). The parent's role in helping the ADHD child with peer relationships. CHADDER, 6, 17-18.

Henley, M., Ramsey, R. S., \& Algozzine, R. (1993). Characteristics of and strategies for teaching students with mild disabilities. Boston: Allyn \& Bacon. 
Holmgren, V. S. (1996). Elementary school counseling: An expanding role. Boston: Allyn \& Bacon.

Horn, W. (1991). Additive effects of psychostimulants, parent training, and self-control therapy with ADHD children. Journal of the American Academy of Child and Adolescent Psychiatry, 30, 233-240.

Individuals with Disabilities Education Act Amendments of 1997, PL 105-17, 105th Congress, 1st session.

Kauffman, J. M. (1997). Characteristics of emotional and behavioral disorders in children and youth. Columbus, $\mathrm{OH}$ : Merrill.

Keenan, S. (1993, October). Planning for inclusion: Program elements that support teachers and students with EIBD. Keynote address at Council for Children with Behavioral Disorders Working Forum, "Inclusion: Ensuring Appropriate Services to Children/Youth with Emotional/Behavioral Disorders," Saint Louis, MO.

Kling, B. (1997). Empowering teachers to use successful strategies. Teaching Exceptional Children, 30(2), 20-24

Kramer, B., \& Wright, D. (1994). Inclusive educational workshop. CA: Diagnostic Center.

Maes, W. (1978). Counseling for exceptional children. Counseling and Human Development, 10, 8-12.

McDowell, W. A., Coven, A. B., \& Eash, V. C. (1979). The handicapped: Special needs and strategies for counseling. Personnel and Guidance Journal, 58, 228-232.

Newby, R., Fischer, M., \& Roman, M. (1991). Parent training for families of children with ADHD. School Psychology Review, 20, 252-255.

Patterson, G. R. (1986). Performance models for antisocial boys. American Psychologist, 41, 432-444.

Pelham, W. E., Vodde-Hamilton, M., Murphy, D. A., Greenstein, J. L., \& Vallano, G. (1991). The effects of methylphenidate on ADHD adolescents in recreational, peer group, and classroom settings. Journal of Clinical Child Psychology, 20, 293-300.

Pierangelo, R., \& Jacoby, R. (1996). Parents complete special education guide. West Nyack, NY: Center for Applied Research in Education.

Polloway, E., Epstein, M., \& Cullinan, D. (1985). Prevalence of behavior problems among educable mentally retarded students. Education and Training of the Mentally Retarded, 20, 3-13.

Quinn, P. (1992). Putting on the brakes. New York: Magination.

Rief, S. E. (1993). How to reach and teach $A D D / A D H D$ children. West Nyack, NY: Center for Applied Research in Education.

Rosenberg, M. S., \& Edmond-Rosenberg, I. (1994). The special education sourcebook: A teacher guide to programs, materials, and information sources. Bethesda, MD: Woodbine House.
Salend, S. (1983). Using hypothetical examples to sensitize nonhandicapped students to their handicapped peers. School Counselor, 33, 306-310.

Seligman, M. (1985). Handicapped children and their families. Journal of Counseling and Development, 64, 274-277.

Silver, L. B. (1992). The misunderstood child. New York: TAB Books.

Silverman, L. K. (1993). Counseling the gifted and talented. Denver: Love Publishing.

Sinason, V. (1997). Your handicapped child. Los Angeles, CA: Warwick.

Smith, S. L. (1991). Succeeding against the odds: How the learning disabled can realize their promise. New York: Penguin Putnam.

Stevens, R. J., \& Slavin, R. E. (1991). When cooperative teaming improves the achievement of students with mild disabilities: A response to Tateyama-Smezek. Exceptional Children, 57, 276-280.

Tarver Behring, S., \& Ingraham, C. L. (1998). Culture as a central component to consultation: A call to the field. Journal of Educational and Psychological Consultation, 9, 57-72.

Tarver Behring, S., \& Spagna, M. E. (1997). School counselors as chance agents toward full inclusion. Arizona Counseling Journal, 21, 50-57.

Tarver Behring, S., Spagna, M. E., \& Sullivan, J. (1998). School counselors and full inclusion for children with special needs. Professional School Counselor, 1, 51-56.

Taylor, J. F. (1994). Helping your hyperactive/attention deficit child. New York: Prima.

Thompson, C. L., \& Rudolph, L. B. (1988). Counseling Children. Pacific Grove, CA: Brooks/Cole.

Tucker, R. L., Shepard, J., \& Hurst, J. (1986). Training school counselors to work with students with handicapping conditions. Counselor Education and Supervision, 26, 56-60.

U.S. Department of Education. (2000). Twenty-second annual report to Congress on the implementation of the Individuals with Disabilities Education Act. Washington, DC: Author.

U.S. Department of Education. (2001). Twenty-third annual report to Congress on the implementation of the Individuals with Disabilities Education Act. Washington, DC: Government Printing Office.

U.S. Department of Education. (2002). A new era: Revitalizing special education for children and their families. Washington, DC: Government Printing Office.

Westman, J. C. (1990). Handbook of learning disabilities: A multisystem approach. Boston: Allyn \& Bacon.

Zirkel, P. A., \& Gluckman, B. (1997). ADD/ADHD students and Section 504. Principal, May 1997, 47-48. 